\title{
Oral lipomas in a Brazilian population: A 10-year study and analysis of 450 cases reported in the literature
}

\author{
Eduardo-Costa Studart-Soares ${ }^{1}$, Fábio-Wildson-Gurgel Costa ${ }^{2}$, Fabrício-Bitu Sousa ${ }^{3}$, Ana-Paula-Negreiros- \\ Nunes Alves ${ }^{3}$, Rafael-Lima-Verde Osterne ${ }^{4}$
}

\begin{abstract}
${ }^{1}$ DDS,MS,PhD, Associate professor, Division of Stomatology and Oral Surgery, Department of Clinical Dentistry, School of Dentistry, Federal University of Ceará, Brazil

${ }^{2}$ DDS,MS, Assistant professor, Division of Stomatology, Department of Clinical Dentistry, School of Dentistry, Federal University of Ceará Campus Sobral

${ }^{3}$ DDS,MS,PhD, Adjunct professor, Division of Oral Pathology, Department of Clinical Dentistry, Federal University of Ceará

${ }^{4}$ DDS,MS, Assistant professor, Division of Pathology, Department of Morphology, School of Medicine, Fortaleza University, Ceará
\end{abstract}

Correspondence:

Rua Professor Otávio Lobo, 540

60176-050, Fortaleza

Ceará, Brazil

estudart@yahoo.com.br

Received: $25 / 08 / 2009$

Accepted: 21/02/2010

Studart-Soares EC, Costa FWG, Sousa FB, Alves APNN, Osterne RLV. Oral lipomas in a Brazilian population: A 10-year study and analysis of 450 cases reported in the literature. Med Oral Patol Oral Cir Bucal. 2010 Sep 1;15 (5):e691-6.

http://www.medicinaoral.com/medoralfree01/v15i5/medoralv15i5p691.pdf

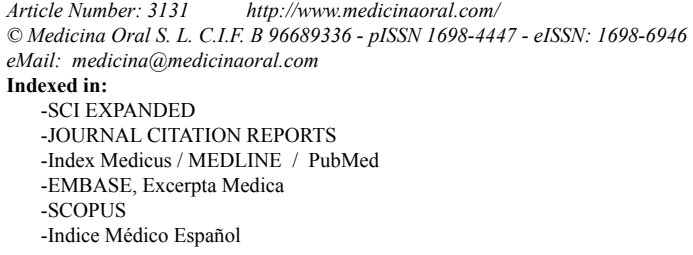

\begin{abstract}
Objectives: Lipomas are common benign mesenchymal neoplasms that rarely occur in the oral cavity and correspond to less than $4.4 \%$ of all benign oral soft tissue tumors. This study describes the clinical, radiological and histological features of cases of oral lipomas seen over a period of 10 years and compared the findings with those reported in the literature.

Study Design: All cases of oral lipomas seen between 1999 and 2009 were retrieved from the archives of the Stomatology Division of the Federal University of Ceará, Brazil. Age, gender, tumor location, clinical findings, duration, histological subtypes, and treatment outcome were recorded. In addition, the English-language literature was searched for studies published between 1966 and 2009.

Results: Ten patients ( 6 women and 4 men) were enrolled in this study. The mean age was 53.4 years (range: 21-73 years). The specific sites involved were the oral mucosa $(n=5)$, vestibule $(n=3)$, gingiva $(n=1)$, and retromolar region $(n=1)$. The mean size of the tumors was $1.94 \mathrm{~cm}$ (range 1.0 to $3.0 \mathrm{~cm}$ ). Radiographically, only one case appeared as a radiolucent area on occlusal film. Microscopically, 4 cases were classified as simple lipoma, 4 as fibrolipoma, 1 as myxoid lipoma, and 1 as angiolipoma. The duration of the tumors ranged from 2 to 84 months, with a mean duration of 30.4 months. All cases were treated by simple surgical excision and there was no recurrence after a mean post-treatment period of 34.5 months. The findings were compared with 450 cases of oral lipomas reported in the literature.

Conclusions: Lipomas continue to be an uncommon neoplasm of the oral cavity. Radiography is a valuable tool due to the possible occurrence of bone involvement. Surgical excision is the treatment of choice and recurrence is not expected.
\end{abstract}

Key words: Oral lipoma, fibrolipoma, myxoid lipoma, angiolipoma. 


\section{Introduction}

Lipomas are the most common benign mesenchymal tumors in humans. The etiology of lipomas is uncertain and the tumors mainly affect the region of the trunk, shoulders, neck and axilla (1). Involvement of the oral cavity is rare, with lipomas corresponding to less than $4.4 \%$ of all benign oral soft tissue tumors (2). Lipomas are usually soft, well circumscribed, mobile, slow growing, and asymptomatic. The oral mucosa and tongue are the sites predominantly affected in adults (3). Histologically, lipomas can be classified into the following microscopic subtypes: simple lipomas, fibrolipomas, spindle cell lipomas, intramuscular or infiltrating lipomas, salivary gland lipomas, myxoid lipomas, and atypical lipomas $(1,2,4)$. Among these variants, myxoid lipomas and angiolipomas are rarely found in the oral cavity (5).

Most data regarding intraoral lipomas come from western countries and, despite the large number of publications, only a few Brazilian case series of lipomas of the oral cavity are available (6-8). Epidemiological data regarding oral lipomas in Latin American countries are important since the combination of clinical, radiographical and histological characteristics of these tumors permits a better understanding of their biological behavior, diagnosis and management. Thus, the objective of the present study was to describe the clinical, radiographical and histological features of a Brazilian series of oral lipoma cases comprising a period of 10 years and to compare the results with those reported in the literature.

\section{Materials and Methods}

The clinical, radiographical and histopathological data of patients seen at the Division of Stomatology, School of Dentistry, Federal University of Ceará, Brazil, between March 1999 and May 2009 were reviewed. Analysis of 1852 consecutive biopsy specimens yielded 10 cases diagnosed as lipoma. These cases were analyzed retrospectively. The data collected from the database of the Division of Stomatology included patient age and gender, tumor location and size, duration of symptoms, clinical and radiographical features, management, duration of follow-up, and treatment outcome. Microscopic hematoxylin-stained slides of all samples were reviewed by a second pathologist for confirmation of the diagnosis and histological features were evaluated according to the World Health Organization classification of soft tissue tumors $(1,2,4)$. In addition, the English-language literature (Pubmed) was searched for studies published between 1966 and 2009. Case reports and small case series were excluded from the analysis.

\section{Results}

Sex and age

Intraoral lipomas were identified in $10(0.5 \%)$ of the 1852 lesions retrieved from the archives of the Stomato- logy Division comprising a period of 10 years. The study group consisted of 4 men and 6 women (ratio 1:1.5), with a mean age of 53.4 years (range: $21-73$ years).

\section{Clinical data}

All patients presented a painless swelling. In 4 cases, the tumors were described as circumscribed, firm to rubbery and yellow in color. Five of the 10 lipomas were located in the oral mucosa, 3 in the vestibule, 1 in the gingiva, and 1 in the retromolar region. The mean tumor size was $1.9 \mathrm{~cm}$ (range: $1.0-3.0 \mathrm{~cm}$ ), with the largest tumor found in the vestibule measuring $3.0 \mathrm{~cm}$. The duration of the lipomas ranged from 2 to 84 months, mean of 30.4 months. Radiographically, only one case appeared as a radiolucent area on occlusal film (Fig. 1). Histological classification

All tumors were excised, fixed in 10\% buffered formalin and routinely processed for histology (hematoxylin and eosin staining). Microscopic analysis revealed the following histological subtypes (Fig. 2): conventional

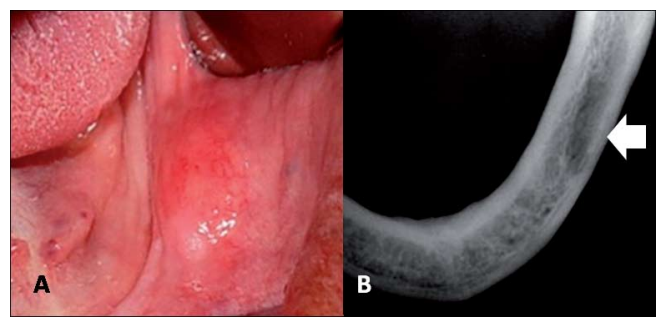

Fig. 1. Clinical presentation of a $3.0-\mathrm{cm}$ nodule characterized by a normal color mucosa (A), which showed a radiolucent area on occlusal radiographic film (B).

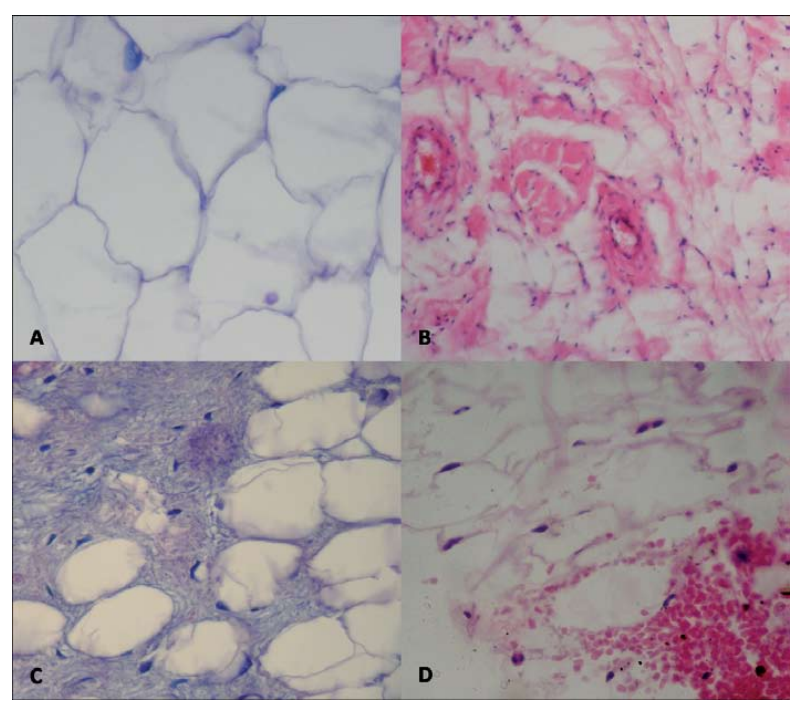

Fig. 2. A) Photomicrograph of a simple lipoma showing mature adipocytes with abundant clear cytoplasm and eccentric nuclei (HE stain, x400). B) Neoplastic fat cells interspersed in fibrous connective tissue characterizing a fibrolipoma (HE stain, x100). C) Mature adipocytes arranged in a myxoid pattern and scattered mast cells characterizing a myxoid lipoma (HE stain, x400). D) Noninfiltrating angiolipoma characterized by the proliferation of blood vessels mixed with neoplastic adipose cells (HE stain, $\mathrm{x} 400$ ). 


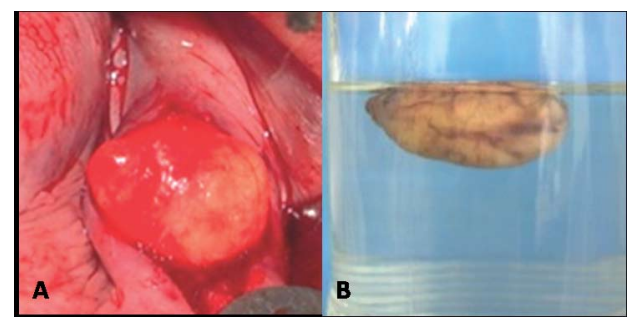

Fig. 3. Intraoperative view of a lipoma showing a well-circumscribed yellow mass (A) and the characteristic aspect of floating in formalin (B).

lipomas $(n=4)$, fibrolipomas $(n=4)$, myxoid lipoma $(n=1)$, and angiolipoma $(n=1)$. A fibrous capsule was observed in most cases. Simple lipomas were characterized by the presence of mature adipose cells arranged in lobules separated by septae and small numbers of blood vessels. Fibrolipomas were diagnosed based on the presence of mature adipose tissue interspersed in broad bands or fascicles of dense connective tissue. Myxoid lipoma was identified based on the presence of mature adipose cells exhibiting a myxomatous component. Angiolipoma was characterized by the presence of mature adipocytes and branching capillary-sized vessels.

Treatment and follow-up

The tumors were excised under local anesthesia according to conventional surgical procedures (Fig. 3). No recurrence was observed after a mean follow-up period of 34.5 months (range: 6 to 86 months). The clinical features, duration of symptoms, histological subtype, and treatment outcome of the 10 cases of oral lipomas are summarized in (Table 1).

\section{Literature review}

A literature search comprising the period between 1966 and 2009 first identified 480 cases of oral and maxillofacial lipomas. However, 30 tumors were excluded due to their location in the parotid gland. Thus, 450 intraoral lipoma cases were retrieved and analyzed. The study period ranged from 4 to 38 years and $52.5 \%$ of the cases occurred in males, with a male to female ratio of 1.1:1. The peak incidence of the tumors was observed in the sixth decade of life. Tumor size ranged from 0.2 to 10 $\mathrm{cm}$ (mean $1.66 \mathrm{~cm}$ ). Most tumors were located in the oral mucosa $(37.56 \%)$ The histological patterns according to the subtypes defined in the present study were, in order of decreasing frequency, simple lipoma (50\%), fibrolipoma (22\%), myxoid lipoma (1.78\%), and angiolipoma $(0.67 \%)$. The comparison of these data with the present findings is shown in (Table 2).

\section{Discussion}

Lipomas of the oral cavity are relatively rare adipose mesenchymal neoplasms (2). Fregnani et al. (9) reported 46 cases of lipomas of the oral cavity, which corresponded to $0.5 \%$ of all tumors diagnosed over a period of 31 years (1970 to 2001) at the Department of Oral Pathology, University of Campinas Dental School. Furlong et al. (2). reported 125 cases of lipomas involving the oral and maxillofacial regions, including the major salivary glands, diagnosed over a period of 34 years. In the present study, 10 cases of lipomas were diagnosed among patients with oral lesions seen between 1999 and 2009 .

No consensus exists regarding the pathogenesis of oral lipomas (10). Today, heredity, fatty degeneration, hor-

Table 1. Clinical-radiographic aspects, histologic subtypes and follow-up of 10 cases of OL.

\begin{tabular}{|c|c|c|c|c|c|c|c|c|}
\hline Case & $\begin{array}{l}\text { Age } \\
\text { (yrs) }\end{array}$ & Sex & Localization & $\begin{array}{l}\text { Size } \\
(\mathrm{cm})\end{array}$ & $\begin{array}{l}\text { Duration } \\
\text { (months) }\end{array}$ & $\begin{array}{c}\text { Radiographic } \\
\text { features }\end{array}$ & $\begin{array}{l}\text { Histologic } \\
\text { subtype }\end{array}$ & $\begin{array}{l}\text { Follow-up } \\
\text { (months) }\end{array}$ \\
\hline 1 & 53 & $\mathrm{~F}$ & Buccal mucosa & 1.5 & 18 & None & Fibrolipoma & 60 \\
\hline 2 & 57 & $\mathrm{~F}$ & Gingiva & 1 & 2 & None & Fibrolipoma & 48 \\
\hline 3 & 63 & $\mathrm{~F}$ & Vestibule & 3 & 6 & Radiolucent area & Lipoma & 38 \\
\hline 4 & 55 & $\mathrm{M}$ & Buccal mucosa & 2 & 72 & None & Myxoid lipoma & 37 \\
\hline 5 & 73 & $\mathrm{M}$ & Vestibule & 2 & 36 & None & Lipoma & 14 \\
\hline 6 & 45 & $\mathrm{~F}$ & Buccal mucosa & 1 & 2 & None & Fibrolipoma & 86 \\
\hline 7 & 60 & $\mathrm{~F}$ & Buccal mucosa & 2 & 6 & None & Lipoma & 14 \\
\hline 8 & 21 & $\mathrm{M}$ & Vestibule & 3 & 84 & None & Lipoma & 28 \\
\hline 9 & 42 & $\mathrm{M}$ & Buccal mucosa & 2 & 48 & None & Fibrolipoma & 14 \\
\hline 10 & 65 & $\mathrm{~F}$ & Retromolar area & 1.5 & $\mathrm{U}$ & None & Angiolipoma & 6 \\
\hline
\end{tabular}

Abbreviators: F, female; M, male; yrs, years; cm, centimeters; U, unknown. 


\begin{tabular}{|c|c|c|c|c|c|c|c|c|c|c|c|c|c|c|c|c|c|}
\hline 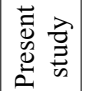 & $\circ$ & 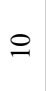 & $\stackrel{\circ}{+}$ & $\stackrel{n}{ت}$ & $\frac{m}{\stackrel{i}{N}}$ & $E$ & $\stackrel{-}{-}$ & $\stackrel{P}{\longrightarrow}$ & in & $m$ & - & - & 0 & $\theta$ & $\nabla$ & - & - \\
\hline 岕 & $\begin{array}{l}\ddot{\circ} \\
\stackrel{\leftrightarrow}{+}\end{array}$ & 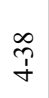 & 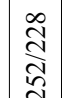 & $\stackrel{ت}{ت}$ & $\begin{array}{c}\widehat{\alpha} \\
\infty\end{array}$ & $\tilde{E}$ & مٌْْ & 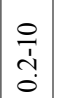 & 它 & $\approx$ & $m$ & iิ & 官 & $\stackrel{2}{\tilde{N}}$ & 2 & $\infty$ & $m 4$ \\
\hline
\end{tabular}

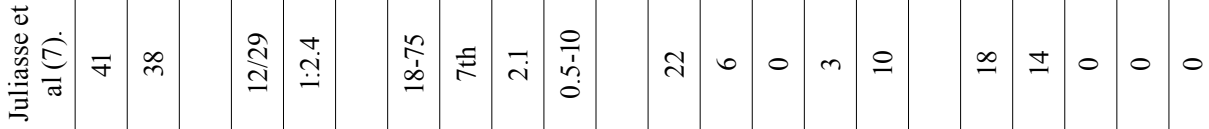

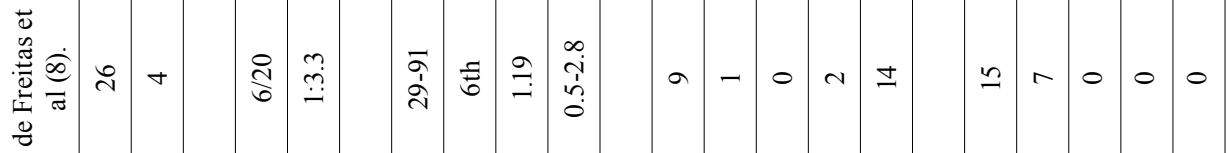

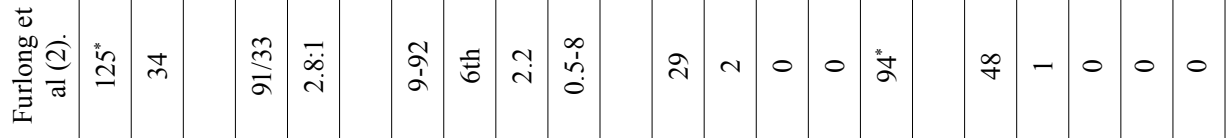

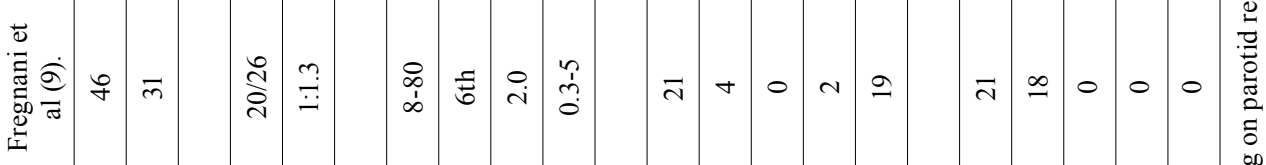

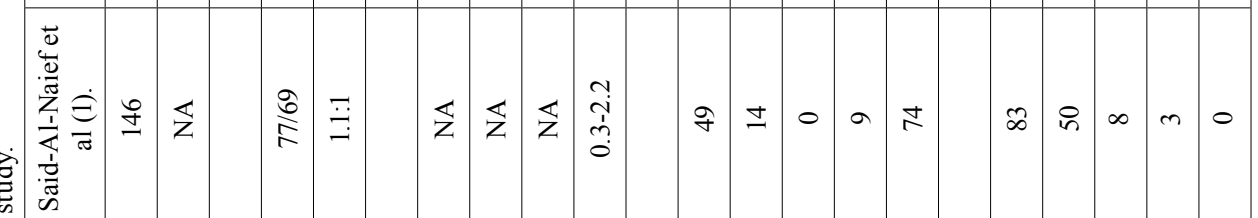
政

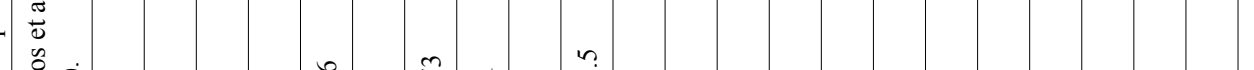

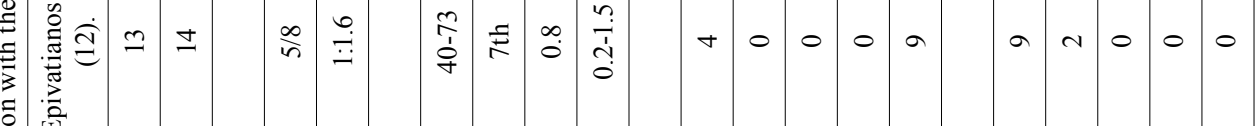

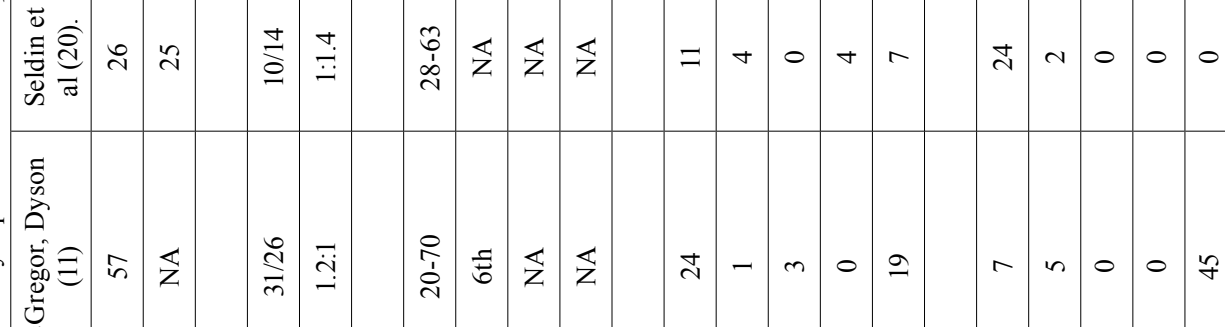
을 
monal basis, trauma, infection, infarction, metaphase of muscle cells, lipoblastic embryonic cell nest in origin and chronic irritation are probable representative theories to elucidate the pattern of a lipoma (11-13). In the present cases, none of the patients had systemic diseases, a history of traumatic episodes, a family history of lipoma, or a specific predisposing event.

Lipomas commonly present as a soft, mobile, lobulated mass of yellow color (14). However, in the present series some tumors appeared as a submucosal swelling covered with normal colored mucosa. According to the literature, in some cases the lining mucosa is thick and the underlying adipose tissue is unnoticeable because of the lack of yellow color (11). These tumors are usually observed in adult patients between the age of 40 and 60 years (2), and generally do not show a gender preference (15). Although we had been obtained a few cases during the study period, a slight preference for females was observed (Table 2). With respect to age, the peak incidence observed in this study agrees with reports in the literature (Table 2).

The most common site of oral lipomas is the oral mucosa (9), a region rich in fatty tissue, followed by the tongue, lips, floor of the mouth, palate and gingival $(2,11)$. This pattern corresponds to the quantity of fat deposits in the oral cavity (13). Our study agrees with Dattilo et al. (16) who reported the gingiva to be a rare site of intraoral lipomas. The clinical course of oral lipomas is generally asymptomatic until they reach a large size. In the present series, one patient reported the presence of an oral lesion for 84 months, whereas the duration of symptoms was 2 and 6 months in two other cases. According to Del Castillo-Pardo de Vera et al. (15), large tumors cause masticatory or swallowing difficulties and dentofacial deformities such as anterior open bite. Dattilo et al. (16) described the case of a giant lipoma arising in the tongue that measured $10.0 \times 9.0$ x $6.0 \mathrm{~cm}$, weighed $200 \mathrm{~g}$, and caused severe functional impairment. No functional or esthetic abnormalities were reported in the present study, probably because of the small size of the tumors (mean of $1.9 \mathrm{~cm}$ ).

Lipomas consist of mature fat cells arranged into lobules that are separated by septa of fibrous connective tissue (12). Although morphologically indistinguishable from normal fat, lipomas differ from normal body fat by the fact that their lipid is not available for metabolism and that they are usually surrounded by a thin fibrous capsule (11). In view of their similar clinical features, other tumors such as thyroglossal duct cysts, ectopic thyrohyoid tissue, pleomorphic adenoma, mucoepidermoid carcinoma, and oral dermoid and lymphoepithelial cysts should be included in the differential diagnosis $(6,11)$. In addition, the occurrence of multiple lipomas is associated with Cowden's syndrome (6). In the present study, all cases were oral solitary tumors.
In the study of Furlong et al. (2) who investigated 125 lipomas in the oral and maxillofacial region, the most frequent histological subtype in the oral cavity was simple lipoma, followed by fibrolipoma. However, some authors reported a similar incidence of lipomas and fibrolipomas (9), as observed in this study. Fibrolipoma has been reported to be more frequent in the cheek mucosa and shows a slight predominance among females. In the present study, fibrolipomas were observed in the gingiva and cheek mucosa, and were more frequent among female patients. Histologically, fibrolipomas consist of fat cells interspersed in broad bands of dense connective tissue (12).

Angiolipoma is a rare histological subtype of lipoma and corresponded to $0.7 \%$ of all oral lipoma cases reviewed in this study (Table 2). Angiolipomas usually affect male adolescents and subjects in their early twenties. Infiltrating angiolipomas are typically diagnosed in older patients (17). In the present series, a 65 -yearold woman exhibited areas of blood vessel formation amidst mature adipose tissue in the absence of fibrin thrombi, findings that led to the histological diagnosis of noninfiltrating angiolipoma. However, in the case of histological observation of abundant vascularity, careful examination should be performed to exclude angiosarcoma and Kaposi's sarcoma (17).

Myxoid lipomas of the oral cavity are rare (1). As shown in (Table 2), there were 8 cases among 450 oral lipomas reported in the English literature. Microscopically, these lipomas were well-circumscribed and contained adipocytes of variable size and myxoid areas (3). One case showing typical histological features of myxoid lipoma was described in the present study.

Although rare, malignant transformation of oral lipomas to liposarcomas has been reported (18). Malignant tumors are characterized by areas of lipoblastic proliferation, myxoid differentiation, cellular pleomorphism, increased vascularity, and mitosis (12). Intramuscular location of lipomas has been reported to be a risk factor for malignancy (18). No intramuscular lipomas were observed in the present study. A useful marker for the differential diagnosis between benign and malignant adipose tissue tumors is the immunohistochemical detection of aP2, a protein expressed by lipoblasts (19). Lipomas may show alterations on conventional radiographs such as those observed in case 3. Similar features detected on occlusal radiographs were only reported by Seldin et al. (20). In this respect, computed tomography, ultrasonography and MRI are valuable tools in most cases $(3,12,19)$.

Patients often request the removal of their lipomas because of concerns regarding growth, cosmetic aspects or symptoms resulting from the compression of local structures (6). No esthetic, functional or neurological abnormalities were observed in the present study. The 
most common symptom described was a slow-growing painless swelling. Surgical resection is the treatment of choice for this tumor (3). However, advantages of suction-assisted lipectomy for medium sized (4 to $10 \mathrm{~cm})$ or large lipomas ( $>10 \mathrm{~cm}$ ) have been reported (18). In the present cases, the treatment of choice was complete resection of the tumors because of their small size. The prognosis of oral lipomas is excellent and recurrence is a rare event. No recurrence was observed in the present series over the 34.5 months of follow-up.

In summary, lipomas are common tumors in humans, but are rare in the oral cavity. The features of oral lipomas observed in the Brazilian population are similar to those reported in the English-language literature. Careful radiographical examination is important in some cases to determine bone involvement. Although simple lipomas continue to be the main histological subtype, this study emphasizes the existence of rare variants such as myxoid lipoma and angiolipoma. In addition, conventional surgery continues to be the standard treatment in these cases.

\section{References}

1. Said-Al-Naief N, Zahurullah FR, Sciubba JJ. Oral spindle cell lipoma. Ann Diagn Pathol. 2001;5:207-15.

2. Furlong MA, Fanburg-Smith JC, Childers EL. Lipoma of the oral and maxillofacial region: Site and subclassification of 125 cases. Oral Surg Oral Med Oral Pathol Oral Radiol Endod. 2004;98:441-50.

3. Zhong LP, Zhao SF, Chen GF, Ping FY. Ultrasonographic appearance of lipoma in the oral and maxillofacial region. Oral Surg Oral Med Oral Pathol Oral Radiol Endod. 2004;98:738-40.

4. De Castro AL, De Castro EV, Felipini RC, Ribeiro AC, Soubhia AM. Osteolipoma of the buccal mucosa. Med Oral Patol Oral Cir Bucal. 2010;15:e347-9.

5. Prado FO, Ito FA, Di Hipólito O Jr, Vargas PA, de Almeida OP, Lopes MA. Pleomorphic lipoma of the face: case report. Oral Dis. 2006; $12: 73-6$

6. Bandéca MC, de Pádua JM, Nadalin MR, Ozório JE, Silva-Sousa YT, da Cruz Perez DE. Oral soft tissue lipomas: a case series. J Can Dent Assoc. 2007;73:431-4.

7. Juliasse LE, Nonaka CF, Pinto LP, Freitas Rde A, Miguel MC. Lipomas of the oral cavity: clinical and histopathologic study of 41 cases in a Brazilian population. Eur Arch Otorhinolaryngol. 2010;267:459-65.

8. De Freitas MA, Freitas VS, de Lima AA, Pereira FB Jr, dos Santos JN. Intraoral lipomas: a study of 26 cases in a Brazilian population. Quintessence Int. 2009;40:79-85.

9. Fregnani ER, Pires FR, Falzoni R, Lopes MA, Vargas PA. Lipomas of the oral cavity: clinical findings, histological classification and proliferative activity of 46 cases. Int J Oral Maxillofac Surg. 2003;32:49-53.

10. Chikui T, Yonetsu K, Yoshiura K, Miwa K, Kanda S, Ozeki S, et al. Imaging findings of lipomas in the orofacial region with $\mathrm{CT}$, US, and MRI. Oral Surg Oral Med Oral Pathol Oral Radiol Endod. 1997;84:88-95.

11. MacGregor AJ, Dyson DP. Oral lipoma. A review of the literature and report of twelve new cases. Oral Surg Oral Med Oral Pathol. 1966;21:770-7.

12. Epivatianos A, Markopoulos AK, Papanayotou P. Benign tumors of adipose tissue of the oral cavity: a clinicopathologic study of 13 cases. J Oral Maxillofac Surg. 2000;58:1113-7.

13. Tan MS, Singh B. Difficulties in diagnosing lesions in the floor of the mouth--report of two rare cases. Ann Acad Med Singapore. 2004;33:72-6.

14. Chidzonga MM, Mahomva L, Marimo C. Gigantic tongue lipoma: a case report. Med Oral Patol Oral Cir Bucal. 2006;11:E437-9.

15. Del Castillo-Pardo de Vera JL, Cebrián-Carretero JL, GómezGarcia E. Ulcera crónica lingual inducida por lipoma de la cavidad oral. caso clinico. Med Oral. 2004; 9:163-6.

16. Dattilo DJ, Ige JT, Nwana EJ. Intraoral lipoma of the tongue and submandibular space: report of a case. J Oral Maxillofac Surg. 1996;54:915-7.

17. Altug HA, Sahin S, Sencimen M, Dogan N, Erdogan O. Noninfiltrating angiolipoma of the cheek: a case report and review of the literature. J Oral Sci. 2009;51:137-9.

18. Silistreli OK, Durmuş EU, Ulusal BG, Oztan Y, Görgü M. What should be the treatment modality in giant cutaneous lipomas? Review of the literature and report of 4 cases. Br J Plast Surg. 2005;58:394-8.

19. Bennett JH, Shousha S, Puddle B, Athanasou NA. Immunohistochemical identification of tumours of adipocytic differentiation using an antibody to aP2 protein. J Clin Pathol. 1995;48:950-4.

20. Seldin HM, Seldin SD, Rakower W, Jarrett WJ. Lipomas of the oral cavity: report of 26 cases. J Oral Surg. 1967;25:270-4. 